\title{
Performance of Thrust Airfoil Bearing for Oil-Free Turbomachinery
}

\author{
Zbigniew Kozanecki $^{1}$ Jakub Łagodziński ${ }^{1} \cdot$ Eliza Tkacz $^{1} \cdot$ Kacper Miazga $^{1}$ \\ Received: 11 November 2016 / Revised: 11 December 2016 / Accepted: 21 December 2016 / Published online: 1 June 2018 \\ (c) The Author(s) 2018
}

\begin{abstract}
Introduction During operation of any turbomachinery, the pressure distribution on rotor parts, i.e., impellers, causes an occurrence of radial and thrust forces. These forces must be transferred by the bearings to the machine casing. One of the most promising bearing types that can be applied in modern high-speed turbomachinery is the airfoil bearings. They have low losses, they can operate at relative high rotational speed, and they usually are lubricated with machine working medium. On the other hand, they have relative low bearing load capacity (DellaCorte and Valco in Tribol Trans 43:795-801, 2000; Radil and DellaCorte in Tribol Trans 53, 771-778, 2010). This problem especially concerns the airfoil thrust bearing. Objective The article describes the performance and operational properties of a thrust airfoil bearing on the test stand. Method The test stand consisted of vertical axis electric motor with thrust plate attached to the shaft. The test covered a wide range of loads and rotational speeds. At these various conditions, the bearing frictional torque was measured. Indirectly, the power loses were calculated depending on the applied load and the shaft rotational speed. At last, after the test, the wear of top foil coating was inspected visually.
\end{abstract}

Keywords Airfoil bearings · Oil-free turbomachinery $\cdot$ Thrust bearing

\section{Introduction}

During the designing of modern turbomachinery, a constructor faces many engineering problems. Usually, the designed machine should be as compact and lightweight as possible, and should have relative high efficiency. In some solutions, one would like to simplify the machine and avoid the seals. These demands imply that considered compressor or turbine must operate at relatively high rotational speed. No seals mean that the bearings should utilize the working medium also as a lubricating medium. Such requirements effectively narrow the available choice of types of bearings. One of the

Jakub Łagodziński

jakub.lagodzinski@p.lodz.pl

Zbigniew Kozanecki

zkozan@p.lodz.pl

Eliza Tkacz

eliza.tkacz@p.lodz.pl

Kacper Miazga

kacper.miazga@p.lodz.pl

1 Institute of Turbomachinery, Lodz University of Technology, 219/223 Wólczańska Str., 90-924 Lodz, Poland bearing types that are able to fulfill the described demands is the airfoil bearings.

The airfoil bearings (Fig. 1) are self-acting type of bearing that utilize gas, usually the air as their lubricating medium. At low rotational speed, the foil bearing operates in dry friction conditions. Above the limit speed, the gas film forms in the air gap and lifts-off the journal. Due to the utilization of air as a lubricant, the foil bearings have very low frictional losses and can operate at high rotational speed [3]. On the other hand, they have some important drawbacks like low bearing load capacity and high frictional torque during startup. The frictional contact between the top foil and the journal enforces an application of the antifriction coatings that are able to withstand numerous startups and rundowns of the machine $[1,2]$. Despite these drawbacks, the airfoil bearings have found their applications in high-speed turbomachinery, i.e., air cycle machines or industrial blowers and compressors. Nowadays, many research facilities worldwide are developing new airfoil bearing conceptions for automotive turbochargers and small jet engines [9]. The main goals of these research programs are to increase the bearing load capacity and to develop durable coating layer that has low friction coefficient and is able to withstand the 

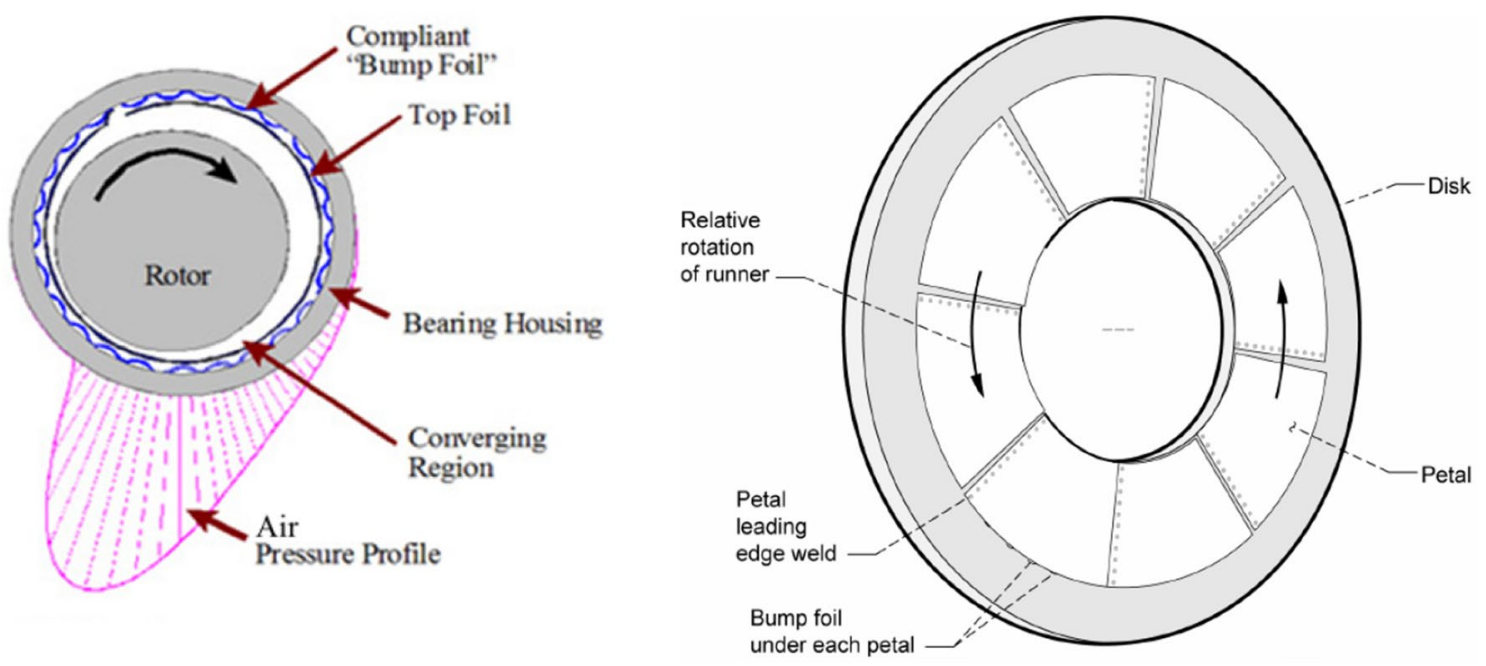

Fig. 1 Airfoil bearing design: journal (on the left) and thrust (on the right) [8]

high temperature, which feature is especially important in gas turbine solutions [4].

The airfoil bearing research program carried out in the Institute of Turbomachinery at Lodz University of Technology covers many aspects of these innovative rotor supports. One of the developed machines is a high-speed compressor driven by an electric motor. The rotor of the compressor is fully supported in the airfoil bearings. During the operation of radial compressor, the pressure distribution on the impeller causes an occurrence of the thrust and radial forces. Depending of the discharge pressure, the thrust force can achieve significant values. This force is transferred to the machine casing through the thrust bearing. For proper and reliable operation, the thrust bearing must have sufficient bearing load capacity. The purpose of research program presented in this article is to evaluate the admissible airfoil thrust bearing load capacity.

\section{Thrust Foil Bearing Design and Operation}

The thrust foil bearing lifting surface is divided into a few segments known as petals (Fig. 2). Under the top foil petals, there are bump foil segments. Both types of segment are welded to greater plate called the main foil. These elements form together the thrust foil bearing structure (Fig. 3).

The principle of operation of the thrust foil bearing is presented in Fig. 4. At startup, below the lift-off speed, a frictional contact between the top foil and the thrust runner occurs. Above the lift-off speed, the air is pressed into the

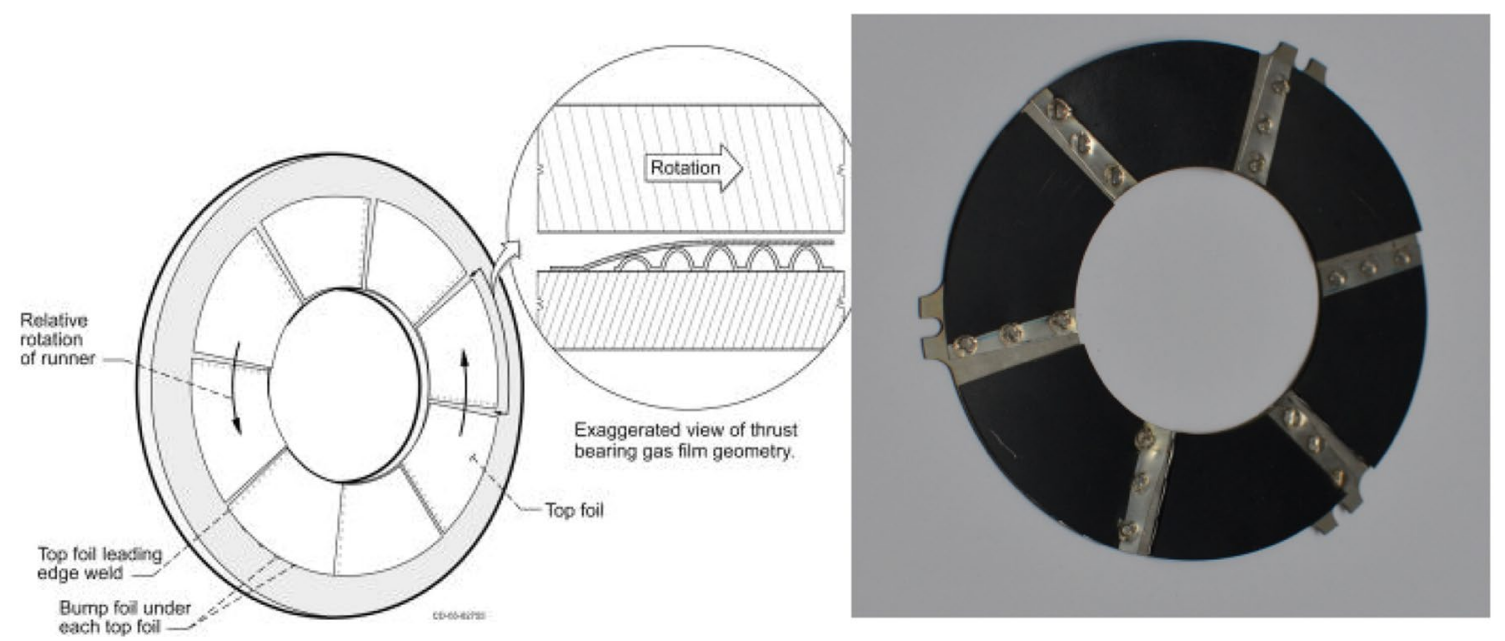

Fig. 2 Thrust foil bearing design and construction [7] 

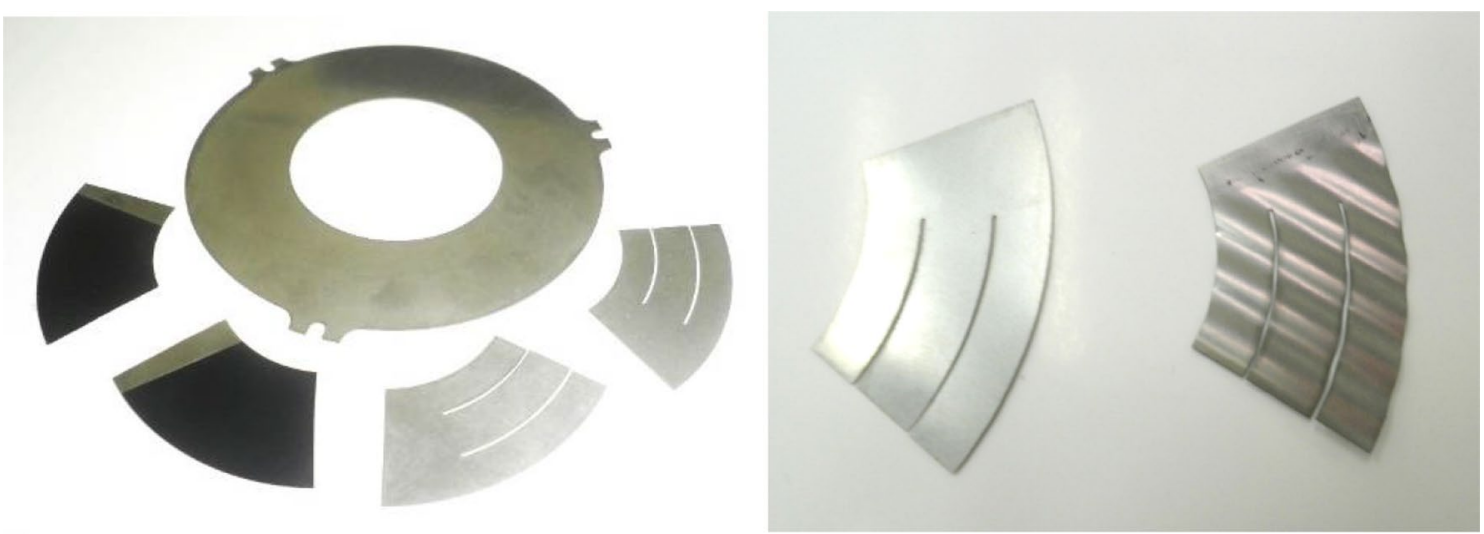

Fig. 3 Thrust bearing structure components. On the right: forming of bump segment

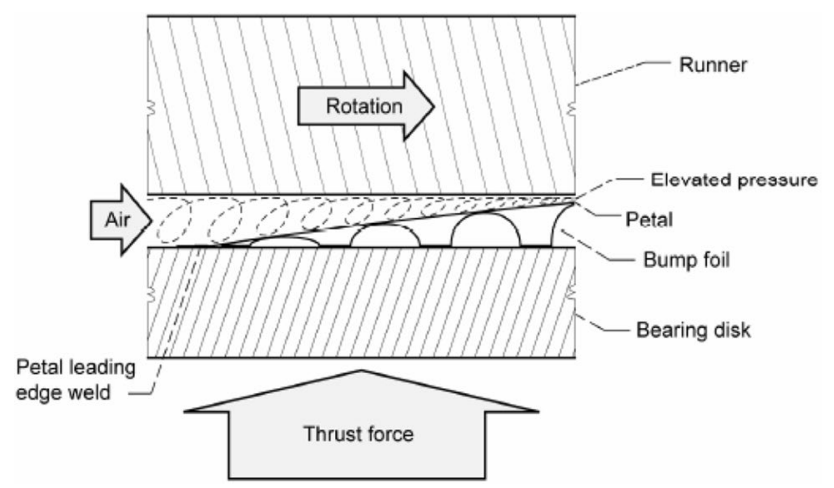

Fig. 4 Thrust bearing operating principle [7]

bearing gap. This phenomenon forms an area of elevated pressure on each petal [10]. The elevated pressure results in the occurrence of bearing reaction force that balances the machine thrust load force.

\section{Test Bench}

The test bench (Fig. 5) is consisted of the electric motor (1) attached vertically to the base (3) and the table top (4). The motor shaft (6) has a trust plate (10) attached to one end. The thrust foil structure (7) is attached to the center body (8) and is pressed against the thrust plate. The center body is floating inside of the aerostatic bearing sleeve (9). This solution allowed for torque measurement system to operate smoothly and without seizures. The torque measurement system consisted of the wire connecting the center body pin (12) to the lever (13). The lever was fixed to the force sensor (14) mounted to the base (3). The rotational speed was measured by optical rpm sensor (5). The load was applied to the horizontal beam (11) (Fig. 6).

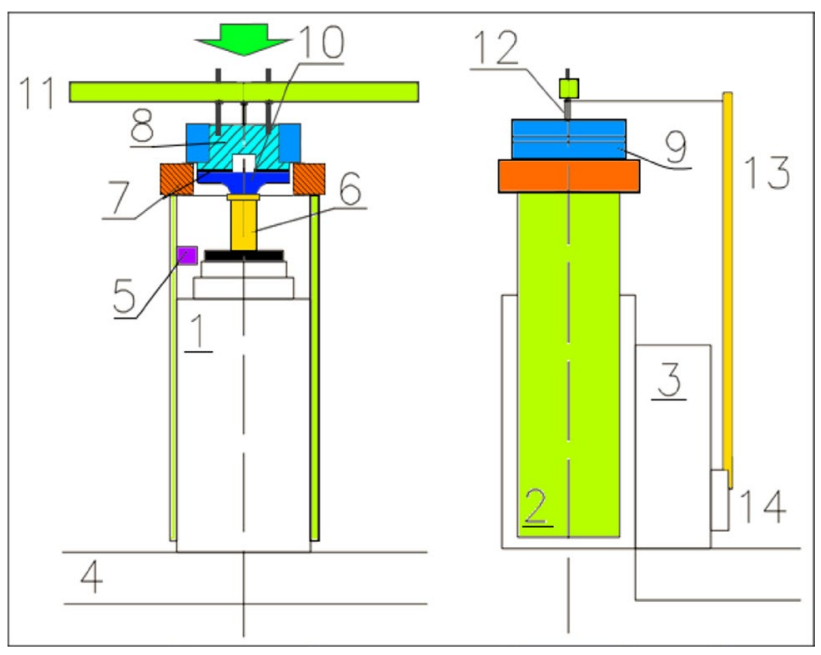

Fig. 5 Thrust airfoil test bench diagram

The research program covered the range of speeds from 200 to $400 \mathrm{~Hz}$. The set boundary values come from the minimal safe speed for thrust foil bearing and maximal allowable speed of electric motor. The range of applied load varied from no load (neglecting the mass of the center body) up to $5667 \mathrm{~kg}$. The maximum safe load was set in accordance with the present state of knowledge about the thrust foil bearings. This value allowed us to heavy load the bearing, with quite low probability of destroying it (Fig. 7).

\section{Experimental Results}

Figure 8 presents the frictional torque of the thrust foil bearing recorded during startup with no load attached to the bearing. One can observe the frictional torque peaks that occurred at low speed during the startup and slow down of 


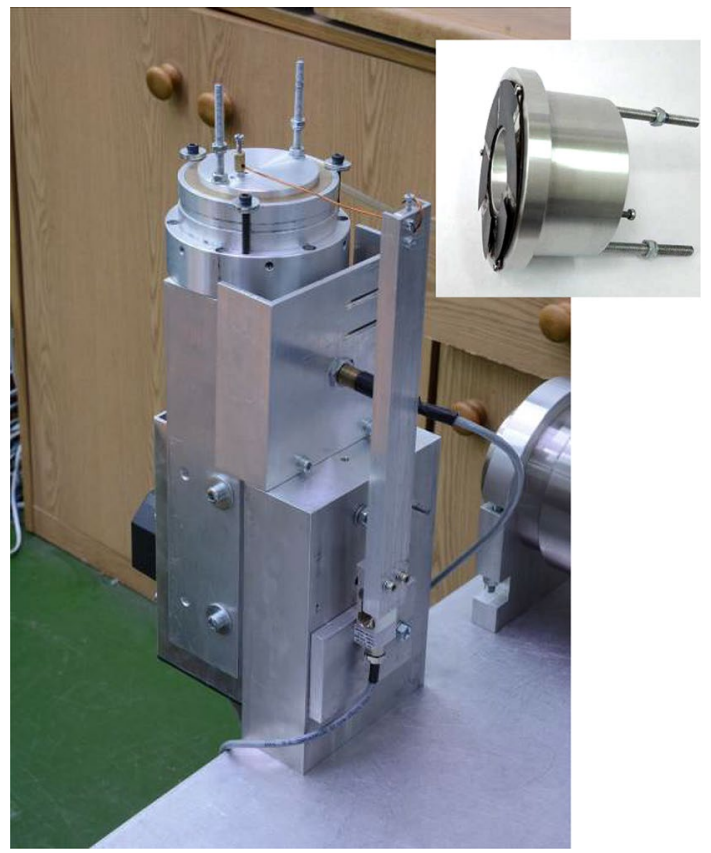

Fig. 6 Left: Test bench mounted to the table. Upper right: Thrust foil structure attached to the center body. Lower right: center body inside the aerostatic bearing sleeve and wire attaching pin to the lever is shown

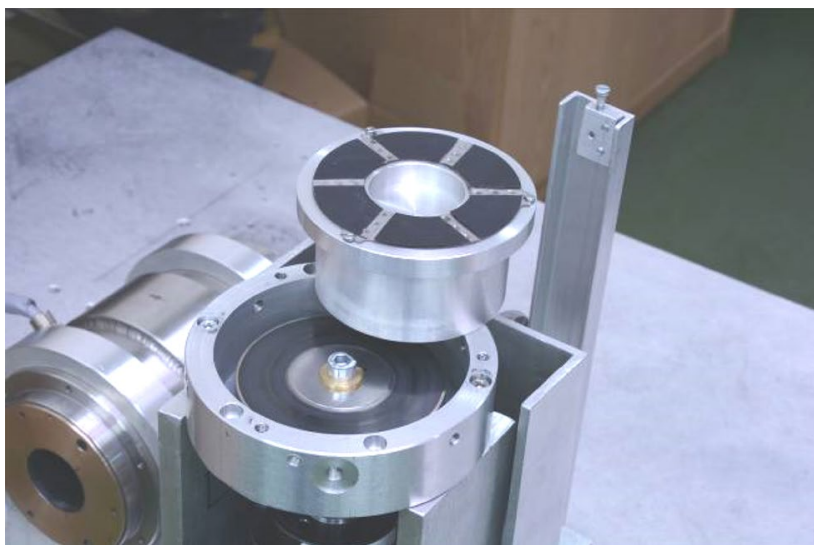

Fig. 7 Center body with foil structure attached is prepared to assembly into the test bench. The thrust plate is visible inside the casing

the shaft. During the normal operation at set speed, the frictional torque is barely measureable. The presented range of data was recorded in approx. $60 \mathrm{~s}$.

Figure 9 presents the frictional torque of the thrust foil bearing recorded during startup with full load attached to the bearing. This load was equal to $5.667 \mathrm{~kg}$ of weight. It can be observed that, at low rotational speed, the frictional torque is noticeable and achieves value of $200 \mathrm{Nmm}$. With increasing shaft rotational speed, the frictional torque decreases down to the minimum value of $75 \mathrm{Nmm}$ at $n=400 \mathrm{~Hz}$. It can be

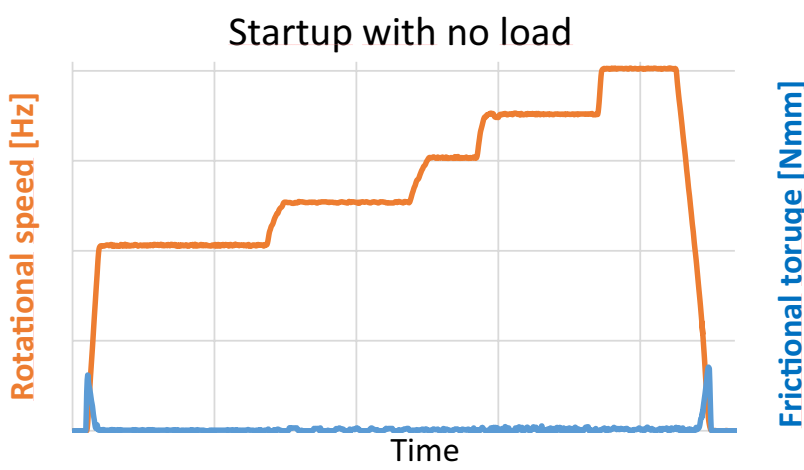

Fig. 8 Startup of the test bench with no load applied on the tested thrust bearing

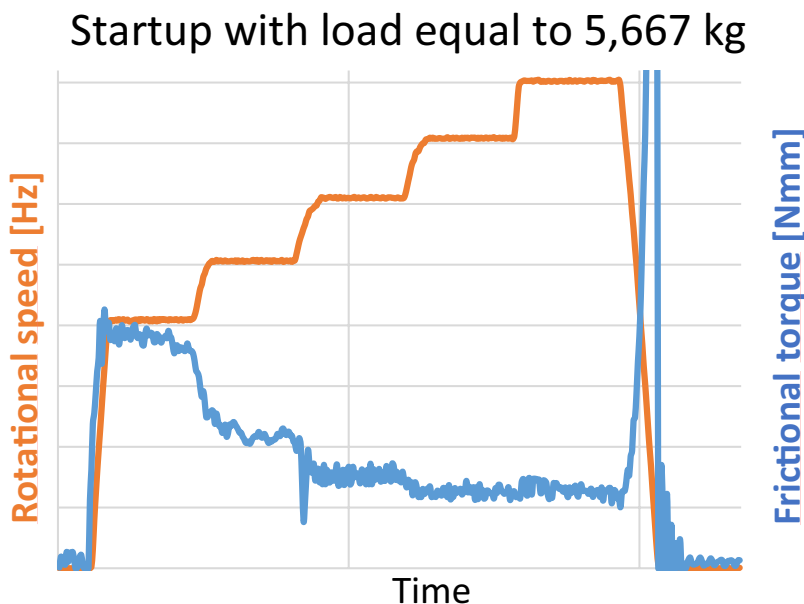

Fig. 9 Startup cycle recorded for full load applied

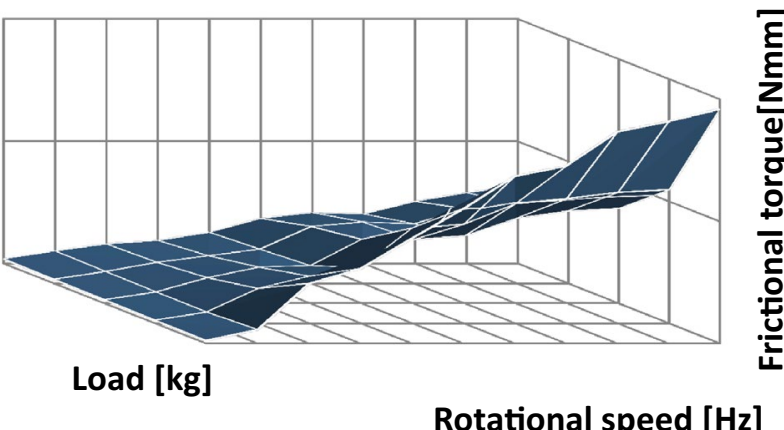

Fig. 10 Thrust foil bearing frictional torque map vs. rotational speed and load

also observed that the machine coast down is very abrupt at the end. The frictional torque at this moment achieves maximum value above $600 \mathrm{Nmm}$.

Figure 10 presents the thrust foil bearing frictional torque map. These values are recorded at set speed and with applied 


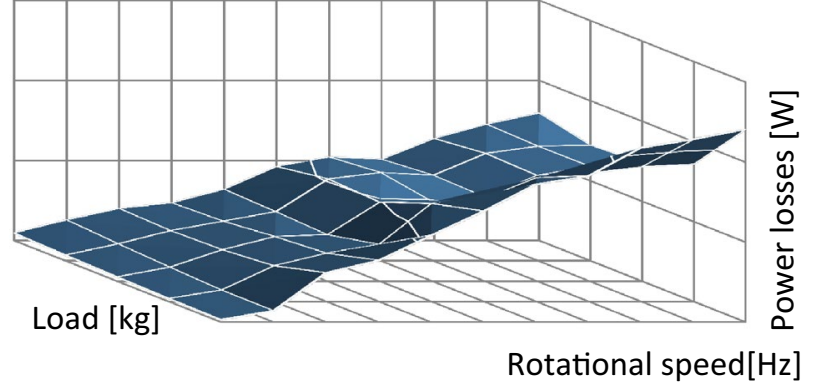

Fig. 11 Thrust foil bearing map of power losses vs. speed and applied load

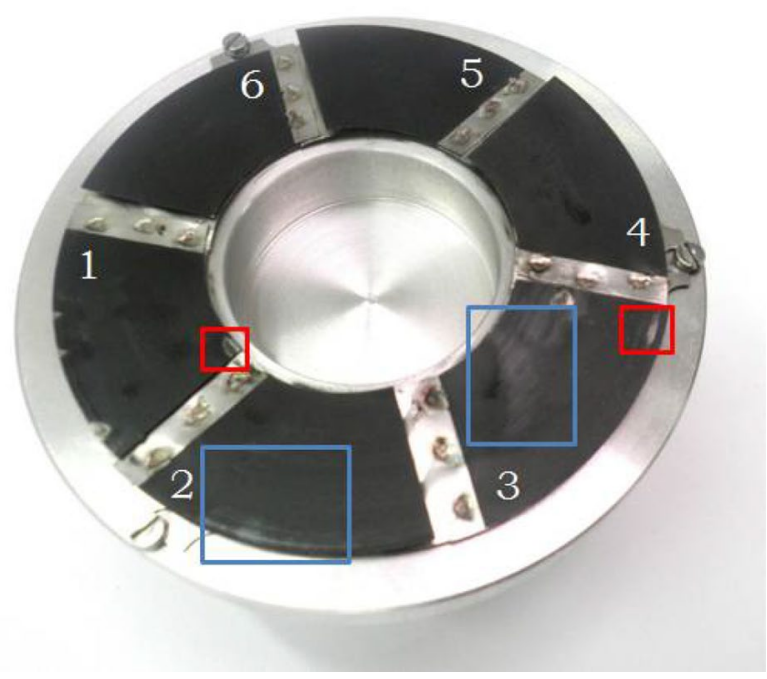

Fig. 12 Top foil surface after the series of tests

load. It can be observed that the highest value occurred ad $200 \mathrm{~Hz}$ and $5.667 \mathrm{~kg}$ of load. At these conditions, the frictional torque achieves value of almost $100 \mathrm{Nmm}$. It is noticeable that the torque characteristic is more responsive to speed change under a heavy load. At light load, the torque map is almost flat. Figure 11 presents the power losses map of the investigated thrust bearing. This picture is similar to the torque map as presented in Fig. 10. The maximum value of generated losses is $120 \mathrm{~W}$ at $200 \mathrm{~Hz}$ and under $5.667 \mathrm{~kg}$ of load. In the foil bearings, the power losses are mostly dissipated into heat.

\section{Top Foil Surface Wear}

Figure 12 presents the top foil surface condition after series of test. It can be noticed that heavy wear is visible on segments No. 1 and No. 3. What is interesting, the segments No. 5 and No. 6 showed no signs of wear. This results in conclusion that these two petals are lower than the rest. The differences between the petal heights are a result of manufacturing precision. In further development, the manufacturing procedure should be improved. This means also that when not all segments take part in the transferring the thrust force, the bearing is not able to fully develop its designed load capacity.

\section{Conclusions}

The presented thrust foil bearing research program provided many valuable insights. This information considered the actual capabilities of developed thrust foil bearings and their limits. From the described research, tests come off the following conclusions:

- The thrust foil bearing has relative low load capacity.

- The frictional torque decreases with increasing shaft rotational velocity and increases with increasing axial load

- At heavy load, the thrust foil bearing torque characteristic is more responsive to shaft rotational speed

- The foil structure manufacturing quality and assembly precision are very important for bearing durability and achievable load capacity

- It should be noticed that the conditions created in the test bench are much tougher for the thrust bearing than in the real turbomachinery. In radial compressor, for example, high thrust force occurs at high rotational speed, and during startup, this force is almost negligible. At the test bench, the real operating conditions were impossible to recreate, because the weight was applied even at $0 \mathrm{rpm}$. There was no possibility to apply the load to rotating shaft only.

- Despite the drawbacks, the foil bearing advantages are the substantial reason to further develop their design and in the effect to widespread their application in turbomachinery.

Open Access This article is distributed under the terms of the Creative Commons Attribution 4.0 International License (http://creativeco mmons.org/licenses/by/4.0/), which permits unrestricted use, distribution, and reproduction in any medium, provided you give appropriate credit to the original author(s) and the source, provide a link to the Creative Commons license, and indicate if changes were made.

\section{References}

1. Miazga K, Tkacz E, Kozanecki Z, Łagodziński J (2011) Investigation of coating materials for air-foil bearings. Cieplne maszyny przepływowe. Turbomachinery 140:149-156 
2. Hashmat H, Hryniewicz P, Walton JF, Willis JP, Jahanmir S, DellaCorte C (2005) Low-friction wear-resistant coatings for hightemperature foil bearings. Tribol Int 38:1059-1075

3. DellaCorte C, Radil KC, Bruckner RJ, Howard SA (2007) Design, fabrication and performance of open source generation I and II compliant hydrodynamic gas foil bearings. NASA/ TM-2007-214691

4. Nalepa K, Pietkiewicz P, Zywica G (2009) Developement of the foil bearing technology. Tech Sci 12:229-240

5. DellaCorte C, Valco MJ (2000) Load capacity estimation of foil air journal bearings for oil-free turbomachinery applications. Tribol Trans 43:795-801

6. Radil KC, DellaCorte C (2010) A three dimensional foil bearing performance map applied to oil free turbomachinery. Tribol Trans 53:771-778

7. Baumann S (2003) An oil-free thrust foil bearing facility design, calibration, and operation, National Aeronautics and Space
Administration John H. Glenn Research Center at Lewis Field Cleveland, Ohio 44135-3191. NASA/TM-2005-213568

8. Bruckner RJ (2012) Performance of simple gas foil thrust bearing in air, National Aeronautics and Space Administration John H. Glenn Research Center at Lewis Field Cleveland, Ohio 441353191. NASA/TM-2012-217262

9. Dykas BD, Tellier DW (2008) A foil thrust bearing test rig for evaluation of high temperature performance and durability. U.S. Army Research Laboratory, Adelphi, MD 20783-1197 and Case Western Reserve University, Cleveland, OH 44106. ARL-MR-0692

10. Dykas BD, Bruckner R, DellaCorte C, Edmonds B, Prahl J (2008) Design, fabrication, and performance of foil gas thrust bearing for microturbomachinery application, National Aeronautics and Space Administration John H. Glenn Research Center at Lewis Field Cleveland, Ohio 44135-3191. NASA/TM-2008-215062; GT2008-50377 